Polish academics

\section{More sackings come to light}

Although martial law in Poland was suspended at the end of last year, several cases are still pending in the courts for offences committed during this period. For the most part, under martial law, the heads of institutes or laboratories tried to minimize the hardship suffered by academics and scholars arrested for continuing trade union activities by granting them unpaid leave of absence for the duration of their captivity. (Those "merely" interned as a preventive measure at the start of martial law were officially assured of job reinstatement.)

Recently, however, Western biologists have been made aware of the case of a young Polish colleague, Jerzy Bal, who has been dismissed from his post at the Warsaw Medical Academy while still in pre-trial detention. The evidence against $\mathrm{Bal}$ apparently consists only of denunciation by informers, so it seems unlikely that he will receive more than a suspended sentence. In that light his dismissal before his case has even been heard seems unnecessarily severe.

Unfortunately, Jerzy Bal had the bad luck to be arrested in connection with what is rapidly developing into a show trial. He was arrested last December as a suspected member of the Interfactory Workers' Solidarity Committee (MRKS), the most radical of the grass-roots underground Solidarity groups set up in the early days of martial law. More than 200 people were arrested on suspicion, of whom 21 were detained pending investigation. Nine of them have so far been brought to trial, but proceedings were halted in March, after a showdown in which the defence counsel, Andrzejewski, was dismissed for contempt for calling the proceedings a "kangaroo court". Comments in the army daily newspaper Zolnierz Woinosci make it clear that the proceedings are designed as an indirect trial of Zbigniew Bujak, the head of the five-man underground Solidarity leadership, and are closely linked with the forthcoming trial of the five "intellectual advisers" of Solidarity from the dissident workers' Defence Committee (KOR) which formally handed over its civil rights commitments to Solidarity in September 1981.

Under these circumstances, the medical academy may well have been panicked into wishing to dissociate itself from $\mathrm{Bal}$, although his friends in Warsaw stress that during police searches of his flat, no evidence was found to link him with MRKS. It would be unfortunate, however, if the pusillanimous attitude of the medical academy were to set a precedent for other academic institutions whose staff fall foul of the security authorities.

Vera Rich

Solar System exploration NASA spells out plans

Washington

THE Solar System exploration committee of the National Aeronautics and Space Administration (NASA) has published its recommendations for a "core programme" of planetary missions to be flown before the end of the century. New features of the programme include using derivatives of commercial Earth-orbital spacecraft for inner planet missions ("Planetary Observers") and a new, modular spacecraft named Mariner Mark II which can be modified for a variety of missions to the outer planets, comets and asteroids. The first four proposed missions are:

- Venus Radar Mapper. To be launched in 1988, and included in the Reagan Administration's 1984 budget proposal, this mission will provide a radar map of the planet's surface with a resolution of approximately one kilometre. The spacecraft will also carry a radar altimeter to provide topographic information and a gravity sensor.

- Mars Geoscience/Climatology Orbiter. This mission, for launch in 1990 , would be the first to use the Planetary Observer spacecraft. Its purpose is to orbit Mars for one martian year gathering information on the planet's surface composition, magnetic fields (if any) and seasonal cycles of carbon dioxide, water and dust that interact between the surface and atmosphere.

- Comet Rendezvous/Asteroid Flyby. The new spacecraft, Mariner Mark II, is recommended to rendezvous with a short period comet as it approaches the Sun and then recedes into deep space. Mariner would carry cameras and remote sensing instruments to study the gas and dust boiling off the comet's nucleus, and sensors to measure the gas and carbon dust composition. Three suitable targets have already been identified - comets Enke, Tempel 2 and Honda-Mrkos-Pajdasakova (HMP) - which could be encountered in the mid-1990s after first flying by a mainbelt asteroid.

- Titan Probe/Radar Mapper. Proposed for launch on some date between 1988 and 1992, this mission would examine the orange-coloured atmosphere that shrouds Saturn's largest moon, and its surface, which is cold enough for methane pools or possibly oceans. The Titan probe could parachute instruments through the atmosphere and send back radar images of the surface. The mission, if upgraded, would also utilize a full-scale Saturn orbiter to study the planet's atmosphere, magnetosphere, satellites and rings. NASA says the combined probe and orbiter would be an ideal candidate for international collaboration.

Excluded from the core programme on the grounds of cost, but still under study by the committee, are missions such as the return of samples from Mars, rovers exploring the martian surface and a buoyant station floating in Titan's atmosphere.

The committee plans to publish the full details of the augmented planetary exploration programme at the end of the year.

Peter David

IMAGE

UNAVAILABLE FOR

COPYRIGHT REASONS 